\title{
COMUNICAÇÃO CIENTÍFICA \\ Observações sobre a ocorrência de Pilumnus floridanus Stimpson (Decapoda, Brachyura, Pilumnidae) na costa do Rio de Janeiro, Brasil
}

\author{
Lydia M. S. Oliveira \& Ĺdia M. Y. Oshiro
}

Estação de Biologia Marinha, Universidade Federal Rural do Rio de Janeiro. Rua Sereder, Itacuruçá, 23880-000

Mangaratiba, Rio de Janeiro, Brasil. E-mail: nydai @ ig.com.br; oshiro@ ufrrj.br

\begin{abstract}
Remarks about the Pilumnus floridanus Stimpson (Decapoda, Brachyura, Pilumnidae) occurrence in Rio de Janeiro coast, Brazil. The specimens were collected in Sepetiba Bay during the winter. Their distribution was formerly known from Off Cape Lookout, North Carolina until Florida, Gulf of Mexico, Yucatan Channel, Honduras, Antilles, Venezuela and Brazil (Alagoas, Sergipe and Bahia).
\end{abstract}

KEY WORDS. Distribution; littoral.

RESUMO. Os espécimes foram coletados na Baía de Sepetiba, Rio de Janeiro no inverno. Sua distribuição era conhecida para Off Cape Lookout, Carolina do Norte até a Flórida, Golfo do México, Canal de Yucatan, Honduras, Antilhas, Venezuela e Brasil (Alagoas, Sergipe e Bahia).

PALAVRAS-CHAVE. Distribuição; litoral.

Pilumnus floridanus Stimpson, 1871 ocorre de Off Cape Lookout, Carolina do Norte até a Flórida, Golfo do México, Canal de Yucatan, Honduras, Antilhas, Venezuela e Brasil (Alagoas, Sergipe, Bahia). É a única espécie do gênero que possui registro somente de Alagoas até a Bahia (Melo 1996, 1998).

Um total de 60 espécimes de Pilumnus floridanus foi coletado manualmente durante as marés baixas (menores ou iguais a zero). Na praia de Ibicuí ( $22^{\circ} 58^{\prime} 43^{\prime \prime}$ S e 44²'30"W) em julho e setembro de 2004 e junho de 2005, foram coletados 55 animais, sendo 28 machos e 27 fêmeas, sendo cinco fêmeas ovígeras. Na Ilha da Marambaia, Ponta do Zumbi (23 4'30"S e 4359'36"W) em julho de 2005 foram coletados três animais, sendo um macho e duas fêmeas, sendo uma fêmea ovígera. Na Lage do Lopes

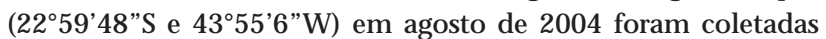
duas fêmeas. A espécie foi encontrada em associação com esponjas, algas, anêmonas, alpheídeos e principalmente com porcelanídeos da espécie M egal obrachium roseum (Rathbun, 1900), na região inferior do litoral e superior do infra-litoral. Os caranguejos foram levados ao laboratório da Estação de Biologia Marinha (EBM), triados, identificados, determinado os sexos, fixados em formaldeído $10 \%$ e conservados em álcool a 70\%. Dois machos e duas fêmeas foram depositados no Museu de Zoologia da Universidade de São Paulo, sob o número MZUSP-16.698.

A variação no comprimento e largura da carapaça nos caranguejos coletados, em machos foi de 8,51 a 6,03 $\mathrm{mm}$ e 3,51 a $2,53 \mathrm{~mm}$, respectivamente; e nas fêmeas foi de 10,26 a 6,78 mm e de 5,03 a $3,49 \mathrm{~mm}$.
Os diferentes locais de coleta na Baía de Sepetiba foram de zonação, e de difícil acesso. Os animais encontrados foram coletados com a maré muito baixa, onde a área descoberta pela água permitiu a visualização e captura. Os espécimes encontrados nos diferentes locais apresentaram o microhabitat muito semel hante, com muitas al gas e associação, principalmente com crustáceos de pequeno porte, o que leva a sugerir que essa escoIha possa estar relacionada com a necessidade de refúgio e reduzida competição.

GouvÊA (1986) acredita que a escolha de microhabitats por caranguejos do litoral rochoso e, principalmente, por parte das espécies menores, está relacionada à necessidade de refúgio, devido ao seu diminuto tamanho e pela ausência de outros meios de defesa.

Esta espécie ocorreu apenas no inverno, provavelmente porque a temperatura do ar, normalmente, é mais amena e, portanto, a força da dessecação é menor. LeVINTon (1982), afirma que a zonação é mais evidente entre os organismos sésseis, porém, os vágeis como os decápodos têm uma distribuição de zonação, devido ao tempo diferenciado de emersão, o qual constitui um estresse térmico, de dessecação e de acesso reduzido ao oxigênio dissolvido e ao alimento. Portanto, se as coletas forem realizadas na região (inferior do litoral e superior do infra-litoral), em microhabitats semelhantes, durante o inverno e em marés baixas (menores ou iguais a zero), possivelmente essa espécie poderá vir a ser incluída na fauna de outras regiões do litoral brasileiro. 


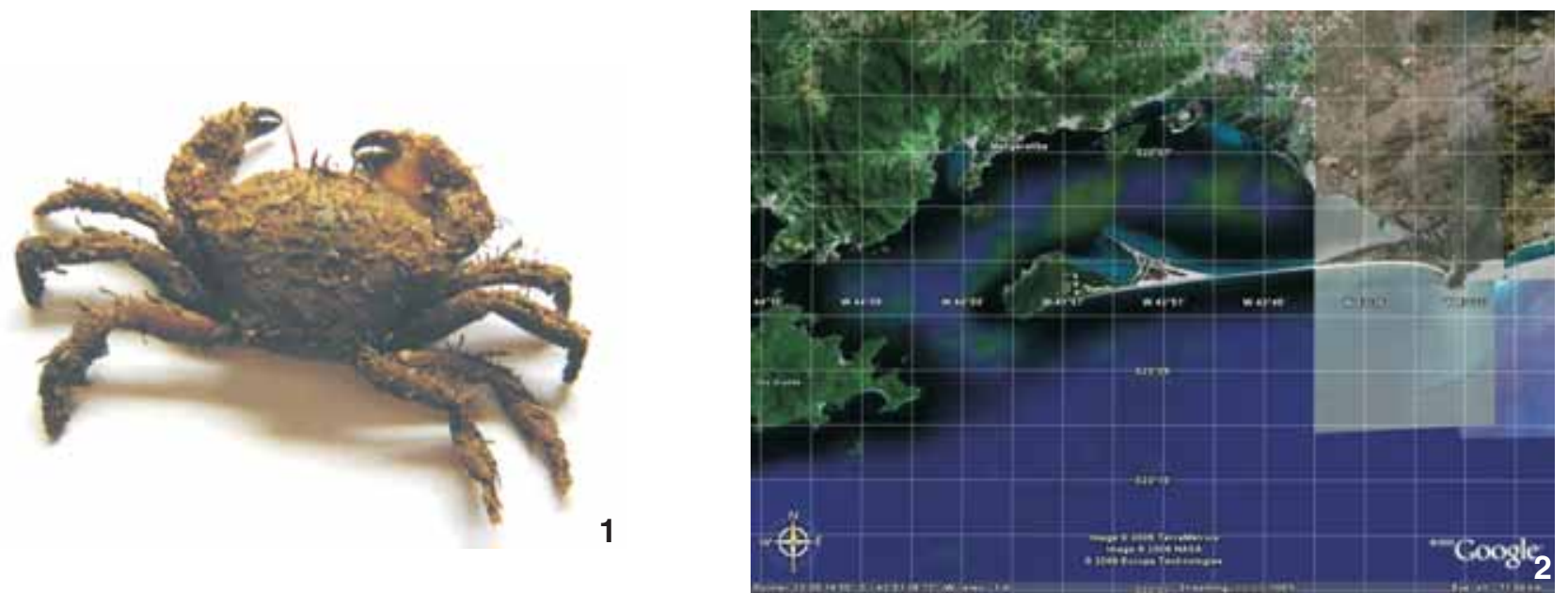

Figuras 1-2. (1) Pilumnus floridanus, vista dorsal; (2) área de ocorrência de P. floridanus na Baía de Sepetiba, Rio de Janeiro, Brasil: (1) Praia de Ibicuí, (2) Ilha da Marambaia, Ponta do zumbi e (3) Lage do Lopes.

\section{AGRADECIMENTOS}

A Gustavo A.S. de Melo (Museu de Zoologia, Universidade de São Paulo), pela confirmação da espécie.

\section{REFERÊNCIAS BIBLIOGRÁFICAS}

GouvÊA, E.P. 1986. A Carcinofauna do Litoral Rochoso de Salvador, BA, e Alguns Aspectos Ecológicos. Ciência e Cultu- ra, Bahia, 38 (2): 346-355.

Levinton, J.S. 1982. Marine ecology. New Jersey, Prentice Hall, $\mathrm{XV}+526 \mathrm{p}$.

Melo,G.A.S. 1996. Manual de identificação dos Brachyura (caranguejos e siris) do litoral brasileiro. São Paulo, Editora Plêiade Fapesp, 603p.

Melo,G.A.S. 1998. Malacostraca - Eucarida. Brachyura. Oxyrhyncha and Brachyrhyncha, p. 455-515. In: P.S. Young (Ed). Catalogue of Crustacea of Brazil. Rio deJaneiro, Museu Nacional, 717p.

Recebido em 10.I.2006; aceito em 30.VIII.2006. 